\title{
O FUTURO DO SETOR DE ENERGIA NO BRASIL SOB A PERSPECTIVA DE UMA SOCIEDADE DO CUSTO MARGINAL ZERO
}

\author{
THE FUTURE OF THE ENERGY SECTOR IN BRAZIL FROM THE \\ PERSPECTIVE OF A ZERO MARGINAL COST SOCIETY
}

\author{
Kiwongui Bizawu ${ }^{1}$ \\ Sandro Mansur Gibran ${ }^{2}$ \\ Eduardo Vieira de Souza Barbosa ${ }^{3}$
}

\section{RESUMO}

A sociedade caminha em vários setores para um custo marginal de operação de produtos e serviços próximos de zero, conforme a abordagem de Jeremy Rifkin em sua obra sobre o tema. $\mathrm{O}$ artigo aborda o olhar do setor elétrico brasileiro sobre essa perspectiva de transformação do mesmo, em especial pelo crescimento exponencial da geração

\footnotetext{
1 Possui graduação em Curso de Direito pela Faculdade de Ciências Jurídicas e Sociais Vianna Júnior (2000), graduação em Institut de Philosophie Saint Augustin - Institut de Philosophie Saint Augustin (1986), graduação em Teologia - Institut de Théologie Eugène de Mazenod (1990), mestrado em Direito pela Pontifícia Universidade Católica de Minas Gerais (2006) e doutorado em Pos-graduacao em Direito pela Pontifícia Universidade Católica de Minas Gerais (2011). Pós-Doutorado na Universidade de Coimbra - Portugal. Ius Gentium Conimbrigae/Centro de Direito, UCPT /(IGC/CDH), Portugal (20172018), Membro do Conselho Curador da Fundação Movimento do Direito e Cidadania (FMDC), Professor do Direito Internacional, Pro-Reitor do PPGD em Direito Ambiental e Desenvolvimento Sustentável da Escola Superior Dom Helder Câmara, professor visitante de direito civil II e III e da "Législation en Matière Economique" da UNIVERSITÉ DU KWANGO (UNIK), sacerdote auxiliar Mitra Arquidiocesana de Belo Horizonte, Congregação do Verbo Divino, professor titular da Escola Superior Dom Helder Câmara e Coordenador do Centro de Estudos afro-brasileiros (AFRODOM) da Escola Superior Dom Helder Câmara com apoio da FAPEMIG. Líder do Grupo de Pesquisa "Direito Animal, Economia, Cultura, Sustentabilité e Proteção Internacional". Membro do Grupo de Pesquisa Estratégica Panamazônia. Tem experiência na área de Direito, com ênfase em DIREITO AMBIENTAL E DESENVOLVIMENTO SUSTENTÁVEL, atuando principalmente nos seguintes temas: direitos humanos, meio ambiente e desenvolvimento sustentável, direito internacional, Direito Internacional Ambiental, Direito internacional Humanitário, sustentabilidade e Direito Animal.

2 Doutor em Direito Econômico e Socioambiental pela Pontifícia Universidade Católica do Paraná. Mestre em Direito Social e Econômico pela Pontifícia Universidade Católica do Paraná. Graduado em Direito pela Faculdade de Direito de Curitiba. É advogado. Professor permanente no Programa de Mestrado e Doutorado em Direito Empresarial e Cidadania do UNICURITIBA. Realizou estágio PósDoutoral na Universidade Federal do Paraná.

${ }^{3}$ Mestrando em Direito Empresarial e Cidadania pelo Centro Universitário Curitiba - UNICURITIBA. Especialista em Direito Constitucional pela Academia Brasileira de Direito Constitucional - ABDConst. Advogado.
} 
descentralizada de energia com a utilização de fontes renováveis, tornando os consumidores em empoderados prosumidores. Neste artigo buscar-se-á analisar a estrutura e regulação do setor elétrico brasileiro que, evidentemente, apesar de ter entes de pesquisa, planejamento, execução e desenvolvimento, não conseguirá acompanhar no aspecto legislativo e regulatório a velocidade da tecnologia e a mudança de comportamento da sociedade. A metodologia utilizada neste estudo é dedutiva, associada a técnicas de pesquisa bibliográfica, por meio da revisão de doutrina, periódicos, artigos científicos e legislação. Conclui-se do estudo que a energia elétrica, por tudo o que se tem vivenciado, deixa com clareza solar a impressão de que num futuro próximo o prosumidor de energia transformará o setor elétrico, na medida em que haverá a facilitação do acesso à produção e ao consumo descentralizado, diminuindo a ingerência do Estado sobre a demanda e a regulação. Ao projetar o setor elétrico brasileiro no futuro, sob a perspectiva de uma Sociedade de Custo Marginal Zero, tal qual entende Jeremy Rifkin, vê-se que a tendência é que o país, assim como toda a humanidade, não mais tenha qualquer problema de falta de energia, pois a mesma será abundante, com a utilização de tecnologia para o armazenamento de energias renováveis, tal como a solar, a voltaica, a biomassa e o hidrogênio. Essa utilização naturalmente romperá fronteiras, aumentará a concorrência e a autonomia dos consumidores/prosumidores, barateará muito os custos e facilitará a vida das pessoas, como tem acontecido com a maioria das inovações do século XXI. O artigo visa contribuir com a análise acerca do ideário projetado pelo filósofo futurista Jeremy Rifkin à realidade do que se discute hoje no Brasil no setor elétrico, num momento em que ocorre o debate descabido sobre a polêmica "taxação do sol".

PALAVRAS-CHAVE:custo marginal zero; energia renovável; internet da energia;

setor elétrico; fontes de energia.

\begin{abstract}
The society is moving in various sectors towards a marginal cost of operating products and services close to zero, according to Jeremy Rifkin's approach in his work on the theme. The article addresses the Brazilian electricity sector's view of this transformation perspective, especially due to the exponential growth of decentralized energy generation using renewable sources, turning consumers into empowered consumers. This article will seek to analyze the structure and regulation of the Brazilian electricity sector, which, despite having research, planning, execution and development entities, will not be able to monitor the speed of technology and behavior change in the legislative and regulatory aspects of society. The methodology used in this study is deductive, associated with bibliographic research techniques, through the review of doctrine, periodicals, scientific articles and legislation. It is concluded from the study that the electric energy, for all that has been experienced, grants with solar clarity the impression that in the near future the energy consumer will transform the form of the electric generation, insofar as there will be easier access to electricity decentralized production and consumption, reducing State interference with demand and regulation. When projecting the Brazilian electric sector in the future, under the perspective of a Zero Marginal Cost Society, as understood by Jeremy Rifkin, it is seen that the tendency is that the country, as well as all humanity, no longer has any problem of lack of energy, as it will be abundant, with the use of technology for the storage of renewable energies, such as solar, voltaic, biomass and hydrogen. Such use will naturally break
\end{abstract}


boundaries, increase competition and the autonomy of consumers and prosumers, make costs much cheaper and make people's lives easier, as has happened with most of the innovations of the 21 st century. The article aims to contribute to the analysis of the ideas projected by the futuristic philosopher Jeremy Rifkin to the reality of what is being discussed today in Brazil in the electricity sector at a time when the unreasonable debate about the controversial "taxation of the sun" occurs.

KEYWORDS: zero marginal cost; renewable energy; internet of energy; energy sources.

\section{INTRODUÇÃO}

Em 2014, o estadunidense Jeremy Rifkin publicou sua obra denominada The Zero Marginal Cost Society (RIFKIN, 2014), na qual questiona o futuro da sociedade capitalista da forma como a conhecemos hoje. Segundo a tese apresentada no livro, que gerou muita repercussão, a incessante busca por produtividade - própria da economia capitalista - é tão exitosa que chegará um momento em que o custo marginal de determinadas atividades econômicas será muito próximo de zero.

A alta velocidade dos avanços tecnológicos trará uma rápida modificação nos mais variados âmbitos sociais. Jeremy Rifkin explora na sua obra a "internet das coisas" ${ }^{4}$, que, em seu entender, num futuro próximo, bilhões de sensores conectarão tudo e todos e alimentarão uma infraestrutura inteligente de informações compartilhadas dando máxima eficiência a produtos e serviços.

Dentre as áreas a serem transformadas por esta nova realidade, está o crescimento exponencial das energias renováveis, que serão responsáveis por $80 \%$ da geração total de energia até 2040 de forma altamente descentralizada, o que poderá (ou deverá) reduzir os custos marginais da energia para próximo de zero, eis que ninguém controla sua fonte de geração, que é o sol.

A partir dessa previsível futura realidade no setor de energia, o presente artigo tem por objetivo tratar da fase de transição vivida hodiernamente pelo setor elétrico Brasileiro, altamente regulado pelo Estado e, como se sabe, no que tange à polêmica sobre a propagada "taxação do sol", analisar o que se pode esperar do crescimento da exploração de fontes de energia pelos prosumidores. Esse neologismo cunhado por

\footnotetext{
${ }^{4}$ Segundo Rifkin "a Internet das Coisas é a primeira revolução de infraestrutura inteligente da história, que irá conectar do equipamento, empresa, residência e veículo em uma rede inteligente..."
} 
Alvin Tofler já é realidade na economia global, como acontece na área de hotelaria com o Airbnb, no transporte com o Uber e na energia com as placas fotovoltaicas.

Sob essa perspectiva, buscar-se-á analisar a estrutura e regulação do Setor Elétrico Brasileiro que, evidentemente, apesar de ter entes de pesquisa, planejamento, execução e desenvolvimento, não conseguirá acompanhar no aspecto legislativo e regulatório a velocidade da tecnologia e a mudança de comportamento da sociedade.

A temática é relevante hodiernamente, no Brasil, em especial pelo fato de que está em curso uma polêmica sobre a propagada "taxação do sol", pela qual busca-se trazer ao leitor condições para opinar como e qual será o futuro da regulação da geração distribuída com a plena ciência de que os avanços tecnológicos e a inovação comportamental desse ramo serão inafastáveis. A Internet da Energia trará consigo uma mudança de comportamento econômico e social e os steakholders do setor deverão identificar os limites de sua atuação e intervenção.

A metodologia utilizada neste estudo é dedutiva, associada a técnicas de pesquisa bibliográfica, por meio da revisão de doutrina, periódicos, artigos científicos e legislação, buscando contribuir com o debate acerca do que será o futuro do setor ele. Após uma breve inserção do problema apresentado, que é o futuro do setor de energia, a partir da Internet das Coisas, a Internet da Energia e o Custo Marginal próximo de zero, que são conceitos abordados na obra de Rifkin, a qual é o fio condutor do presente artigo, passa-se a um contexto do setor de energia no Brasil e, na sequência o texto abordará a discussão acerca do crescimento da geração distribuída no país e a polêmica "taxação do sol" tão debatida, para, ao fim, fazer considerações sobre o futuro do setor nesse ambiente desenfreado de inovações tecnológicas que indubitavelmente modificarão a forma de se viver da humanidade na já sentida Terceira Revolução Industrial.

\section{REFERENCIAL TEÓRICO}

Para a construção da presente pesquisa foram utilizadas, além das obras já citadas de TOFFLER e, especialmente de RIFKIN, a qual é o fio condutor da argumentação, a menção a artigos, dissertações, notícias, bem assim de manuais do setor de energia, como o de BRAGA.

Apesar da inexorável mudança nos comportamentos sociais e na economia a partir da internet das coisas e do custo marginal quase zero das operações produtivas, 
foi feito um corte para a análise apenas do setor de energia, na medida em que este impacta diretamente na vida das pessoas e do desenvolvimento de todos os demais setores. Todos os tecidos sociais de um Estado como o Brasil dependem de sua infraestrutura elétrica para sobreviver.

Como o País hoje experimenta uma discussão sobre a nova regulamentação das energias renováveis, utilizar-se-á dados recentes (ANEEL, CCEE e EPE) e artigos especializados sobre o tema, como os apresentados pelos consultores da BCG (Boston Consulting Group).

\section{A INTERNET DAS COISAS E A ENERGIA GRATUITA: A TESE DE JEREMY RIFKIN}

Basta parar para analisar os itens ao redor por alguns instantes para perceber que a tecnologia vem modificando a forma de viver da população e a economia global de forma avassaladora.

Os smartphones são um dos melhores exemplos desta afirmação. Nos aparelhos de telefone cabem serviços de banco, de transporte, de saúde, de alimentação, de lazer e de relacionamento entre outros. Grande parte da humanidade não concebe mais viver sem as facilidades dos smartphones.

No Brasil, até a década de 90, as linhas telefônicas eram caríssimas, eram patrimônio, bens suscetíveis de comercialização e sucessão. Hoje, as linhas (número de telefone) tem um custo marginal, mas os aparelhos, a partir das utilities acoplada a eles, e é claro, desde que haja conexão à internet, são um bem precioso; e não apenas no aspecto de produto, mas sim, enquanto vetores de informação; não somente na seara pessoal, mas especialmente para as empresas de tecnologia, que conectam as pessoas em segundo se integram dados e sistemas de forma rápida e global.

Dentre as empresas mais valiosas do mundo figuram companhias que produzem bens e serviços com o custo unitário muito baixo ao consumidor. São empresas que se utilizam da inovação tecnológica para inovar no modo de vida da sociedade.

Um dos exemplos de empresas de tecnologia que inovam a forma de viver-se é representado pelo Airbnb, que é a maior rede hoteleira do mundo, sem possuir um único hotel. É apenas um conector de demanda entre o proprietário do imóvel e o consumidor que, por sua vez, também pode ser um "hospedeiro" em seu imóvel ao mesmo tempo em que é hóspede de um terceiro, sem a necessidade de ter contato direto com a contraparte. 
Outro exemplo nítido a ilustrar este tema é a Uber, a maior frota de carros de transporte do mundo, sem possuir um único veículo. A consolidação da Uber - aliada a outros fatores como a preocupação com sustentabilidade - modificou a forma de pensarse em transporte urbano em todo o mundo. Estudos já apontam que os jovens não mais querem ter bens como veículo e imóvel. A economia está mudando e o comportamento está mudando também.

Ademais, a economia global vem sofrendo várias mudanças em razão do enorme salto de produtividade da tecnologia em todos os ramos. Em várias áreas, a eficiência e a capacidade dos produtos e serviços estão crescendo exponencialmente, de forma que abaixará o seu custo e aumentará a produtividade desses setores.

Guilherme Ferreira da Costa esclarece sobre a crescente descentralização da sociedade e seus motivos:

\footnotetext{
O desenvolvimento tecnológico apresentado nas últimas décadas cumpre papel decisivo para que a sociedade continue migrando de um sistema centralizado, pautado em firmas verticalmente integradas e intensivas em capital financeiro, para uma sociedade descentralizada e lateralmente distribuída. Jeremy Rifkin argumenta que os principais momentos disruptivos da sociedade ocorreram com o desenvolvimento de uma nova matriz de comunicação, energia e transporte. Para o autor, o presente século parece reunir ferramentas tecnológicas suficientemente fortes para a consolidação de um novo paradigma. (2017, p. 19).
}

Rifkin, ao tratar das "curvas exponenciais" quando menciona as mudanças em franca expansão com a "internet das coisas", cita a transformação da sociedade em vários ramos a partir da inversa proporção entre a capacidade de desempenho das inúmeras formas de tecnologia, em contrapartida ao aumento de velocidade de sua eficiência e do decréscimo significativo no custo dessas tecnologias. Essa mudança faz com que o acesso às inovações beire o custo marginal zero das operações, transformando sobremaneira e de forma exponencial a economia global.

O filósofo estadunidense, rotulado por alguns de futurólogo, pois bradava o fim dos empregos em sua obra publicada em 1995 (RIFKIN, 2004), em vista da crescente automação, a qual ele também retrata ao mencionar a qualidade das impressoras 3D na obra Sociedade de Custo Marginal Zero, afirma que com a Terceira Revolução Industrial o capitalismo passará a não ter tanta importância assim, pois as novas tecnologias da comunicação, convergirão com as energias renováveis transformando a 
sociedade em horizontal, participativa, simples e barata, fortalecendo as economias locais e mais preocupadas com o aspecto social do que apenas com o lucro.

Rifkin argumenta que todas as grandes revoluções que ocorreram na história da humanidade têm em comum o desenvolvimento de um ou mais elementos da matriz da infraestrutura de comunicação, energia e transporte. (RIFKIN, 2016, p. 18). Ele, juntamente com outros autores, defende que a humanidade está prestes a vivenciar esse salto.

O setor de energia é muito explorado por Rifkin, que desenvolveu o tema numa obra específica de 2004, denominada The Hydrogen Economy (RIFKIN, 2004). Em nenhuma outra área de tecnologia discute-se mais exponencialidade do que na indústria da energia renovável.

O poder do armazenamento da tecnologia da energia renovável está experimentando sua própria curva exponencial de crescimento por meio da fonte solar e eólica, com a expectativa de crescimento das fontes geotérmica, biomassa e hídrica. A energia renovável deve contabilizar grandes investimentos de capital em pesquisa, desenvolvimento e distribuição no mercado de cada nova geração de tecnologia.

Outro grande desafio do setor de energia refere-se às companhias, que são forçadas a avançar décadas à frente de seus concorrentes para prever quando lançar inovações ou correr o risco de serem esmagados pela força da curva exponencial. A concorrência no setor de energia é global. O Brasil percebe hoje na área de energia o mesmo efeito que outros ramos da economia já sentem a mais tempo - por se tratar de um setor muito regulado - que é justamente o avanço dos grandes grupos econômicos sobre as empresas nacionais. A concentração no setor de energia tende a ser grande na competição pela busca da maior eficiência e do lucro. As empresas que não acompanharem as inovações serão engolidas.

No que tange às inovações ligadas às energias renováveis, os especialistas preveem que em uma década a tecnologia solar e pequenos aerogeradores serão tão baratos quanto telefones celulares e laptops. Isso muda a forma de pensar-se o setor. Muda o comportamento das empresas e das pessoas. O custo para estabelecer-se uma Internet da Energia (RIFKIN, 2004, p. 103) é muito significativo em termos de infraestrutura, mas o custo marginal de produzir-se cada unidade de energia solar ou eólica é quase zero. A energia renovável, assim como a informação, torna-se praticamente gratuita após contabilizados os custos fixos em pesquisa, desenvolvimento e distribuição. 
Algumas companhias já estão preparadas para esse desafio, especialmente com as utilities agregadas aos serviços de distribuição. Smart grids já são uma realidade em muitas empresas; as grandes distribuidoras de energia já imaginam como beneficiar-se das informações estratégicas que obterão pela Internet das Coisas e não estão preparadas para a nova forma de consumir-se energia. O cidadão, além de consumidor, será prosumidor, pois será muito barato e fácil produzir energia a partir dessa revolução tecnológica.

Os serviços de distribuição de energia estão deixando de ser atividades centralizadas e burocráticas para tornar-se cada vez mais democráticos, dinâmicos e descentralizados, sabendo-se que cresce geometricamente o número de pessoas jurídicas e até físicas que se tornaram microgeradores de energia elétrica, seja para o próprio consumo ou para compensação ou créditos na conta.

O prosumidor, termo cunhado por Alvin Toffler (1990, p. 35), remete ao agente econômico inserido em uma sociedade emergente que é o produtor e o consumidor ao mesmo tempo, exatamente o que se vê na área de energia. A produção em massa, centralizada e verticalmente integrada, é substituída pela produção personalizada. No paradigma da $2^{\mathrm{a}}$. Revolução Industrial - intensiva em capital intensivo, mão de obra barata e repetitiva - a necessidade por padronização era crucial para atingir índices de produtividades satisfatórios; observa-se atualmente o crescimento de um mercado intensivo em tecnologia, capaz de entregar produtividade e personalização a custo marginal próximo de zero. (COSTA, 2017. p. 37).

$\mathrm{O}$ que diferencia a primeira da segunda revoluções industriais em relação às fontes energéticas é a baixa eficiência e o alto impacto ecológico do carvão e do petróleo, respectivamente. A revolução energética em curso, como propõe Rifkin, apoia-se no fato de que as casas e os edifícios residenciais e comerciais tornaram-se potenciais produtores de energia elétrica (limpa), que pode ser compartilhada por meio de redes inteligentes. (ABRAMOVAY, 2014, p. 83).

A partir da revolução energética, a prevista "Internet da Energia", segundo Rifkin, irá mudar a maneira como a eletricidade é gerada e distribuída para a sociedade. $\mathrm{Na}$ próxima era, centenas de milhões de pessoas irão produzir a sua própria energia renovável em casa, na empresa e nas fábricas de forma interligada às informações obtidas e compartilhadas através da internet.

Nessa seara, pode-se afirmar que o impacto na sociedade é ainda mais pronunciado quando considerado o vasto potencial do sol como futura fonte de energia. 
O sol emite 470 exajoules de energia para a Terra a cada 88 minutos - essa cifra corresponde à quantidade de energia que os seres humanos utilizam em apenas um ano. Caso fosse possível armazenar um décimo de $1 \%$ da energia solar que incide na Terra, esse armazenamento forneceria seis vezes a quantidade de energia que se utiliza atualmente na economia global. (RIFKIN, 2106, p. 103).

Apesar de o sol ser claramente a fonte universal de energia, de onde deriva todo o combustível fóssil e outras energias do planeta, esse tipo de combustível representa menos de 0,2\% da combinação atual de fontes de energia; até recentemente, era algo claro de captar e distribuir - o que não é mais o caso. O preço dos equipamentos tende a cair 20\% (RIFKIN, 2106, p. 103) a cada duplicação da capacidade da indústria. A eficiência das células solares aumentou exponencialmente e a energia solar tende a ser tão barata. (RIFKIN, 2016, p. 104).

Apesar de a energia eólica não ser tão comentada no Brasil como outras fontes de energia, tal como a solar, hoje é objeto de polêmica no País, dotada de onipresença no mundo, pelo simples fato de que há vento em todos os locais do planeta.

Rifkin cita um estudo conduzido pela Universidade de Stanford sobre a capacidade do vento global, no qual se chegou à seguinte conclusão: "se $20 \%$ do vento disponível no mundo fosse coletado, isso geraria sete vezes mais energia do que usamos atualmente para alimentar a economia mundial”. (2016, p. 105).

A capacidade eólica tem crescimento exponencial desde o início da década de 1990 e já alcançou paridade com a eletricidade gerada convencionalmente por combustíveis fósseis e energia nuclear em muitas regiões do mundo. Nos últimos 25 anos, a produtividade das turbinas eólicas aumentou em mais de 100 vezes, e a capacidade média por turbina em mais de $1.000 \%$. O aumento de desempenho e produtividade reduziu significativamente o custo da produção, instalação e manutenção, resultando numa duplicação a cada dois anos e meio.

Os céticos ao enorme crescimento das fontes de energia renovável ao redor do planeta argumentam que os subsídios governamentais, na forma de tarifas especiais, impulsionam artificialmente a curva de crescimento. Esse argumento não é objeto de discussão atualmente no Brasil, o que se abordará com mais detalhe na sequência.

Ressalta-se que, em todos os Estados, cada qual com sua peculiaridade econômica, social ou de diretriz de gestão, as energias solar e eólica estão similares à energia convencional, gerada por combustíveis fósseis e por energia nuclear, permitindo que o governo comece a reduzir ou eliminar tarifas. Em pouco tempo, a tendência é que 
a energia perca seu valor, pois a humanidade, através das fontes renováveis, produzirá toda a energia de que necessita a baixos custos.

\section{O SETOR DE ENERGIA NO BRASIL: BREVE CONTEXTO}

Diferentemente de outras áreas da economia, o setor elétrico é totalmente dependente de intervenção estatal, na sua ausência, um Estado ou região pode entrar em colapso. Despiciendo afirmar-se que quase todas as necessidades da vida humana atual dependem de energia elétrica e a sua ausência em determinada região fatalmente levará em poucos dias ao colapso da mesma.

A Vice Presidente da Câmara de Comercialização de Energia Elétrica, Solange David e Alexandre Viana, estudiosos do tema, ao tratar da dependência que as populações têm da energia elétrica, afirmam que "dada a importância da energia elétrica, entende-se que o Estado deve ser protagonista em criar um ambiente regulatório e um desenho de mercado que promova a eficiência econômica e o acesso universal." (2016, p. 880).

A energia elétrica desempenha um papel fundamental para o desenvolvimento e o crescimento econômicos, destacando que o acesso à eletricidade é um indicador básico mundial para aferir-se o grau de conforto da população e o desenvolvimento de um Estado. Toma-se como exemplo o IDH (Índice de Desenvolvimento Humano), que considera o acesso à energia elétrica como um de seus indicadores essenciais na análise.

O SEB (Setor Elétrico Brasileiro) iniciou seu trabalho a partir de um pequeno negócio privado disperso no nascimento do processo de urbanização brasileiro, transformando-se, posteriormente, em uma indústria estatal chave para a política desenvolvimentista, resultando na segunda metade da década de 90 e nos anos 2000 em um mercado liberalizado, com uma participação privada relevante.

O setor elétrico brasileiro, segundo Alexandre Viana (2016, p. 880), passou ao longo de sua história por três grandes fases:

A primeira foi a fase de interesse local, municipal, de atuação basicamente privada: como bem restrito, particular, o que se justifica pela necessidade de melhoramentos urbanos, como a iluminação pública e o transporte coletivo, no início de desenvolvimento industrial e urbano do País;

Posteriormente veio a fase da federalização e da estatização, de interesse nacional e de iniciativas estatais: energia como serviço público e não mercadoria. $\mathrm{O}$ 
grande marco dessa nova etapa é a presença do Estado representado pelo Código de Águas (Decreto nº. 24.643/1934) e a Constituição de Federal de 1934.

Por fim, a fase mista ou concorrencial, atualmente, regulada, de grande atuação estatal e privada: energia elétrica de interesse nacional, como serviço público e commodity negociável no mercado. Há uma forte atividade de planejamento, combinada com a atividade de operação e de mercado, em que o Estado também atua de forma substancial. (2016, p. 881)

O Brasil, desde a última fase de reestruturação regulatória, promovida a partir da implantação pelo governo federal do Projeto de Reestruturação do Setor Elétrico Brasileiro (Projeto RE-SEB), sob coordenação do Ministério de Minas e Energia e consultoria da firma inglesa Coopers \& Lybrand, tendo por objetivos estimular o investimento no setor elétrico e assegurar a expansão da oferta de energia no País; vislumbrou regular de forma ordenada e estratégica todo o setor, incluindo os steakholders.

Um de seus principais resultados foi a promulgação da Lei $\mathrm{n}^{\circ} .9 .427$, de 26 de dezembro de 1996, que dentre outras inovações, instituiu a Agência Nacional de Energia Elétrica - ANEEL, autarquia sob o regime especial, vinculada ao Ministério das Minas e Energia, com a finalidade de regular e fiscalizar a produção, a transmissão e a comercialização de energia elétrica, em conformidade com as Políticas e Diretrizes do Governo Federal. (BRAGA, 2018, 107).

Em 1997, o Projeto RE-SEB finalizou a minuta do anteprojeto de lei que cria o Mercado Atacadista de Energia (MAE) e o Operador Nacional do Sistema Elétrico (ONS). Com o início da reestruturação do setor elétrico, as empresas de energia começam a ser desverticalizadas - separando seus segmentos de geração, transmissão e distribuição

Em março de 1998, o Mercado Atacadista de Energia Elétrica (MAE) e o Operador Nacional do Sistema Elétrico (ONS) foram instituídos pela Medida Provisória $\mathrm{n}^{\mathrm{o}}$. 1.531-16, convertida dois meses depois na Lei $\mathrm{n}^{\circ} .9 .648$

Em 2004 houve a criação da CCEE, através do Decreto nº 5.177, de 12 de agosto de 2004, que regulamentou os art. $4^{\circ}$. e $5^{\circ}$. da Lei $\mathrm{n}^{\circ} .10 .848$, de 15 de março de 2004, e dispôs sobre a organização, as atribuições e o funcionamento da Câmara de Comercialização de Energia Elétrica - CCEE, pessoa jurídica de direito privado, sem fins lucrativos, sob a regulação e fiscalização da Agência Nacional de Energia Elétrica ANEEL. 
A Empresa de Pesquisa Energética - EPE foi instituída no mesmo ano, com a finalidade de prestar serviços ao Ministério de Minas e Energia (MME) na área de estudos e pesquisas destinadas a subsidiar o planejamento do setor energético, atuando nas áreas de energia elétrica, petróleo e gás natural e seus derivados e biocombustíveis. Trata-se de uma empresa pública federal, integralmente dependente do Orçamento Geral da União. A empresa foi constituída por meio de medida provisória convertida em lei pelo Congresso Nacional - Lei $n^{\circ}$. 10.847, de 15 de março de 2004. E a efetivação se deu em um decreto de agosto de 2004.

A EPE foi criada com o objetivo de resgatar a responsabilidade constitucional do Estado nacional em assegurar as bases para o desenvolvimento sustentável da infraestrutura energética do País. A partir de sua instituição, a atuação da EPE consolidou-se como parte fundamental de um ciclo de atividades que se iniciou com as definições de políticas e diretrizes no âmbito do CNPE - Conselho Nacional de Política Energética e do MME. A partir dessas definições, materializam-se os estudos e as pesquisas que irão efetivamente orientar o desenvolvimento do setor energético brasileiro.

Infere-se do expostos que a estruturação regulatória do setor é extremamente complexa e interligada. Para facilitar a compreensão, apresenta-se adiante uma figura ilustrativa da atual composição de entres ${ }^{5}$ :

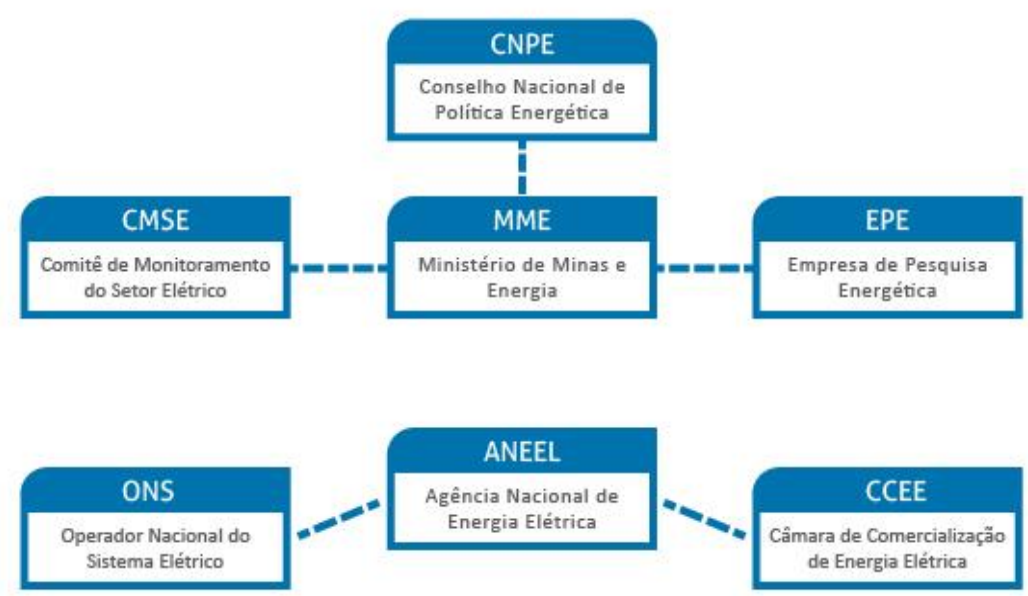

\footnotetext{
${ }^{5}$ CCEE. Disponível em: <https://www.ccee.org.br/portal/faces/pages_publico/ondeatuamos/setor_eletrico?_afrLoop=1469887863935266\&_adf.ctrl-state=bkz9tq9sh_27.>. Acesso em: 5 fev. 2020.
} 
Todas as decisões do setor de energia elétrica são estruturadas no âmbito dessa plêiade de entes de planejamento, orientação e execução, para que o Brasil possa gerar, transmitir, distribuir e comercializar energia de forma equilibrada, com modicidade tarifária e com o atendimento da demanda de consumo da sociedade e de seu desenvolvimento.

Não é o objetivo deste artigo, mas, de modo a esclarecer o leitor que não atua na área de energia, afirmas-se a energia produzida numa localidade não necessariamente será a energia consumida naquela localidade. A geração de energia brasileira é descentralizada. As hidrelétricas - maior fonte de geração do país - geralmente tem localização afastada dos grandes centros de consumo. A distância faz com que toda a estruturação da operação até o atendimento do consumidor na ponta da cadeia produtiva tenha de ser muito eficiente, razão pela qual há a necessidade do controle estatal. Indubitavelmente, é um setor estratégico para o País e, como tal, o Estado deve ser protagonista.

É importante denotar que, fim de 2018, um Estado-membro brasileiro, Roraima, correu sério risco de ficar sem energia por ser o único Estado-membro do Brasil fora do sistema interligado nacional, denominado SIN. Roraima é abastecido em dois terços pela importação de energia gerada na Usina Guri, na Venezuela. O restante de seu consumo vem de termelétricas. Por ser um sistema isolado, recebe o subsídio de Conta de Consumo de Combustíveis (CCC) embutido na Conta de Desenvolvimento Energético (CDE), rateada entre todos os brasileiros na conta de energia. (KAFRUNI, 2018).

Dessa forma, todos os brasileiros pagam pela eventual ineficiência no planejamento ou execução do sistema.

Para entender o que é o SIN - Sistema Interligado Nacional, vale citar o que consta do sítio eletrônico do ONS - Operador Nacional do Sistema:

O sistema de produção e transmissão de energia elétrica do Brasil é um sistema hidro-termo-eólico de grande porte, com predominância de usinas hidrelétricas e com múltiplos proprietários. O Sistema Interligado Nacional é constituído por quatro subsistemas: Sul, Sudeste/Centro-Oeste, Nordeste e a maior parte da região Norte.

A interconexão dos sistemas elétricos, por meio da malha de transmissão, propicia a transferência de energia entre subsistemas, permite a obtenção de ganhos sinérgicos e explora a diversidade entre os regimes hidrológicos das bacias. A integração dos recursos de geração e transmissão permite o atendimento ao mercado com segurança e economicidade. 
A capacidade instalada de geração do SIN é composta, principalmente, por usinas hidrelétricas distribuídas em dezesseis bacias hidrográficas nas diferentes regiões do país. Nos últimos anos, a instalação de usinas eólicas, principalmente nas regiões Nordeste e Sul, apresentou um forte crescimento, aumentando a importância dessa geração para o atendimento do mercado. As usinas térmicas, em geral localizadas nas proximidades dos principais centros de carga, desempenham papel estratégico relevante, pois contribuem para a segurança do SIN. Essas usinas são despachadas em função das condições hidrológicas vigentes, permitindo a gestão dos estoques de água armazenada nos reservatórios das usinas hidrelétricas, para assegurar o atendimento futuro. Os sistemas de transmissão integram as diferentes fontes de produção de energia e possibilitam o suprimento do mercado consumidor."

A matriz elétrica ${ }^{7}$ brasileira é sensivelmente diferente da distribuição das fontes no resto do mundo. Nesse sentido, é possível citar que o potencial do Brasil para que ocorra o crescimento das energias renováveis é imenso. Segundo dados da Empresa de Pesquisa Energética - EPE, a matriz elétrica brasileira é baseada em fontes renováveis de energia, ao contrário da matriz elétrica mundial. Este fato é ótimo para o Brasil, pois além de terem menores custos de operação, as usinas que geram energia a partir de fontes renováveis geralmente emitem bem menos gases de estufa. Grande parte da energia elétrica gerada no Brasil vem de usinas hidrelétricas. A energia eólica e a fotovoltaica também vem crescendo demasiadamente, contribuindo para que a matriz elétrica nacional continue sendo renovável em sua maior parte.

Em virtude desta característica nacional, aspectos maiores foram trazidos ao País como discussões ambientais, tributárias, regulatórias e sobre a intervenção do poder público sobre o interesse privado. As discussões são cíclicas, mas se acirram quando o aspecto político-ideológico é colocado na mesa para discussão.

A geração de energia elétrica no mundo é baseada principalmente em combustíveis fósseis, como o carvão, o óleo e o gás natural em termelétricas. O carvão representa $38,3 \%$ da fonte mundial; o gás natural representa $23,1 \%$; a energia hidráulica representa 16,6\%; a energia nuclear representa 10,4\%; as energias solar, eólica, geotérmica e outras representam $5,6 \%$; o petróleo e seus derivados representam 3,7\%; a

\footnotetext{
${ }^{6}$ NOS. Disponível em:< http://www.ons.org.br/paginas/sobre-o-sin/o-que-e-o-sin $>$. Acesso em: 6 fev. 2020.

${ }^{7}$ Cabe aqui um esclarecimento de que matriz energética não é o mesmo que matriz elétrica. A matriz energética representa o conjunto de fontes de energia disponíveis para movimentar tudo o que depende de energia para funcionar (ex.: carros), a matriz elétrica é formada pelo conjunto de fontes disponíveis apenas para a geração de energia elétrica. Portanto, a matriz elétrica é parte da matriz energética.
} 
biomassa representa 2,3\%, segundo dados do IEA (International Energy Agency) em $2018^{8}$.

No Brasil, segundo dados da EPE, no Balanço Energético Nacional (BEM) de 2018, as fontes elétricas estão assim dispostas: 65,2\% hidráulica; 10,5\% gás natural; $8,2 \%$ biomassa; $6,9 \%$ solar e eólica; $4,1 \%$ carvão; $2,6 \%$ nuclear e 2,5\% petróleo e derivados.

Assim, comparativamente, de forma aproximada $82 \%$ da matriz elétrica do Brasil é proveniente de fontes renováveis e, em contrapartida, no mundo, as fontes renováveis representam cerca de apenas $24 \%$. Cite-se o gráfica abaixo de forma ilustrativa:

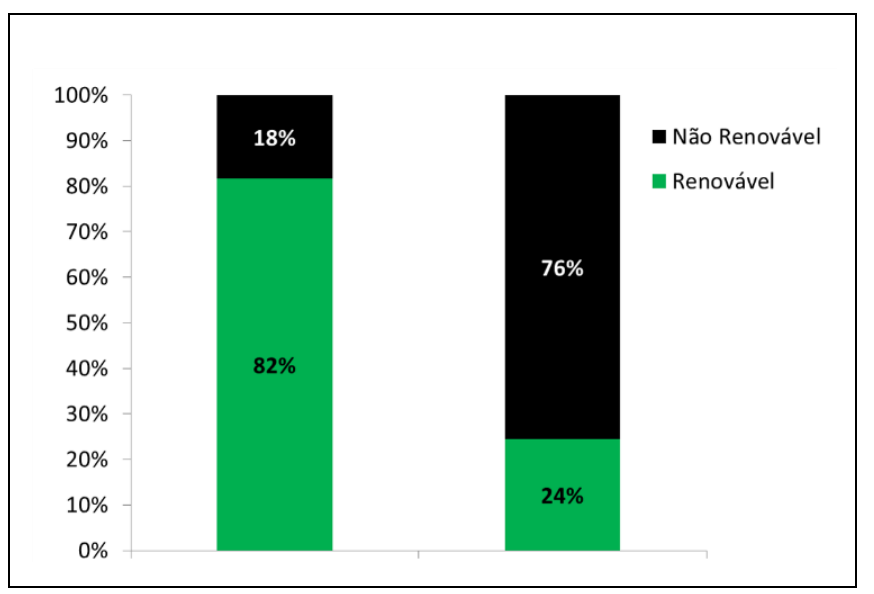

Inegavelmente, em riquezas ambientais o Brasil é muito privilegiado e, se souber aproveitar, perceberá imenso crescimento econômico nas próximas décadas, justamente porque as fontes não renováveis tendem a se esvair.

Recentemente, o mundo acompanhou a repercussão das discussões acerca das queimadas da Amazônia e, polêmicas à parte, o governo brasileiro expôs abertamente o fato de que Estados nações como a França e a Alemanha, que pouco preservaram de suas riquezas naturais, além de terem explorado as riquezas de outros Estados, manifestaram preocupação em relação à política ambiental brasileira, o que, em última análise, fere a soberania nacional.

\footnotetext{
${ }^{8}$ IEA. Shapping a secure and sustainable energy future for all. Disponível em: <https://www.iea.org/>. Acesso em: 3 fev. 2020.
} 
Em tempos de acirramento dos conflitos ao redor do mundo, de enfraquecimento dos blocos continentais e da volta do nacionalismo em algumas regiões do globo, dizer sobre soberania e meio ambiente numa análise não tão ingênua faz muito sentido. Os interesses dos Estados mais ricos, isto é, das grandes corporações que compõem a força desses Estados, é o que lastreia boa parte desta discussão. O tema permeia diversos ramos econômicos e sociais; de um lado, as fronteiras tecnológicas e comerciais estão esvaindo-se e, de outro, muitas das fontes de energia dos países ricos estão esgotandose, restando apenas os recursos de além território.

Neste cenário de muitas "quase-guerras" acontecendo, é de se pensar que um Estado que não garanta energia elétrica à sua população fragiliza-se muito na sua soberania, tanto no aspecto das defesas da fronteira, quanto no aspecto da ingerência de outros Estados sobre sua população. Um exemplo em tela é o conflito ideológico entre a Venezuela e o Brasil, e o fato de que o Estado venezuelano já ameaçou cortar o fornecimento de energia da população de Roraima, como citado anteriormente, num momento crítico em que se observa um grande êxodo de venezuelanos para o Brasil, via Roraima.

O setor elétrico traz em sua estruturação a demonstração clara da discussão travada em vários âmbitos acadêmicos sobre os limites do interesse público acima das relações privadas. ${ }^{9}$ (AFONSO DA, 2011, p. 211/214). Trata-se de um setor muito estratégico para o desenvolvimento nacional, com o fornecimento de infraestrutura para o atendimento da grande indústria, gerando emprego, renda e riqueza; de fato, é inconcebível que o Estado não interfira na sua regulação.

\section{A DISCUSSÃO SOBRE O CRESCIMENTO DA GERAÇÃO DISTRIBUÍDA NO BRASIL E SUA REGULAMENTAÇÃO}

O País tem acompanhado uma novela nos últimos meses, cujo enredo enriquecese com a propagação de muitas fake news e da falta de habilidade dos steakholders do setor acerca da propagada "taxação do sol".

Como já esclarecido anteriormente, a geração de energia no Brasil é majoritariamente centralizada, isto é, o despacho das usinas, orientado pelo ONS a

\footnotetext{
${ }^{9}$ Ao citar as teses diferentes de Alexy (otimização) e Dworkin (uma única resposta) - distinção entre regras e princípios: AFONSO DA (2011. p. 211/214).
} 
partir da verificação da demanda versus a geração de energia e outros indicadores, como o risco hídrico, é transmitido pelo SIN e distribuído pelas concessionárias de energia elétrica, que têm contratos de longo prazo adquiridos via leilões promovidos pela ANEEL.

No entanto, cresce exponencialmente a geração de energia descentralizada, como já dito, cujo futuro, conforme previsão de Rifkin, transformará os consumidores em prosumidores, derrubará os custos marginais a aproximadamente zero e demandará uma "refundação" de todo o setor no mundo.

O modelo de geração distribuída pode ser definido como o uso de recursos modulares de pequeno porte, e questiona justamente a forma de expansão da oferta de energia elétrica. (BARBOSA, 2014, p. 40). A geração distribuída de energia elétrica emprega diversas tecnologias diferentes. A possibilidade de geração próxima aos centros urbanos traz mais segurança e qualidade no abastecimento, na medida em que diversifica a matriz, diminuindo a exposição ao risco inerente a cada fonte energética. Do ponto de vista da comunidade local onde se localiza a unidade geradora, destacamse positivamente a criação de empregos, a contribuição para o desenvolvimento local e o aumento da confiabilidade do fornecimento. Além disso, a transição para uma matriz distribuída requer mão de obra inevitavelmente local. Pelo exposto, fica evidente o inarredável crescimento dessa forma de geração de energia.

Ainda que a transição para o modelo de geração distribuída exija valor considerável de capital investido, há uma garantia de retorno imediato, a partir da economia na conta de energia decorrente da autogeração, que possibilita a tomada de crédito a juros baixos. Desse modo, torna-se menos arriscado e oneroso lateralizar o estabelecimento de uma matriz renovável de escala mundial. Para Rifkin, este processo deve evoluir rápido, em grande parte, porque a conectividade global da internet possibilita o engajamento ativo de bilhões de pessoas na construção da nova matriz energética.

Há ganhos também no aspecto ambiental, pois, com a geração distribuída, há redução das emissões dos gases de efeito estufa, redução do impacto ambiental ao dispensar as grandes instalações de geração e de linhas de transmissão e menor dependência do uso de fontes energéticas não-renováveis. 
Além de utilizar os bens comuns da natureza - sol, água, vento -, é intensiva em tecnologia e promove o empoderamento dos indivíduos a partir da autogeração - os prosumidores.

No Brasil, a regulamentação da geração distribuída ainda é muito recente. Tratase da Resolução Normativa ANEEL nº. 482/2012 (que alterou a Resolução Normativa n'. 414/2010), atualizada pela Resolução Normativa $n^{\circ}$. 687/2015, que estabeleceu ao consumidor brasileiro a permissão e os requisitos para gerar sua própria energia elétrica a partir de fontes renováveis ou cogeração qualificada, além de fornecer o excedente do consumido para a rede de distribuição de sua localidade.

A ANEEL assim define a micro e minigeração distribuída:

\begin{abstract}
Trata-se da micro e da minigeração distribuídas de energia elétrica, inovações que podem aliar economia financeira, consciência socioambiental e autossustentabilidade.

Os estímulos à geração distribuída se justificam pelos potenciais benefícios que tal modalidade pode proporcionar ao sistema elétrico. Entre eles, estão o adiamento de investimentos em expansão dos sistemas de transmissão e distribuição, o baixo impacto ambiental, a redução no carregamento das redes, a minimização das perdas e a diversificação da matriz energética."10
\end{abstract}

Atualmente, a disciplina do setor prevê a permissão do uso de qualquer fonte renovável além da cogeração qualificada, denominando-se microgeração distribuída a central geradora com a potência instalada de até 75 quilowatts (KW) e minigeração distribuída com a potência acima de $75 \mathrm{KW}$ e menor ou igual a $5 \mathrm{MW}$, conectadas na rede de distribuição por meio de instalações de unidades consumidoras.

O mecanismo de cogeração estabelece que, quando a quantidade de energia gerada em determinado mês for superior à energia consumida naquele período, o consumidor fica com créditos que podem ser utilizados para diminuir a fatura dos meses seguintes. A norma também estabelece a possibilidade de instalação em condomínios, sendo as porcentagens de compensação repartidas por múltiplas unidades consumidoras. É possível, ainda, a geração compartilhada entre consorciados ou cooperados pela utilização da energia gerada para a redução das tarifas. Caso a energia injetada na rede seja superior ao consumo, gera-se um crédito que pode ser compensado em até 60 meses.

\footnotetext{
${ }^{10}$ ANEEL. Disponível em: <http://www.aneel.gov.br/geracao-distribuida>. Acesso em; 5 fev. 2020.
} 
Até 2019, a ANEEL não estabelecia um custo para esses geradores e o governo, através de linhas de crédito do BNDES, fomentou o incentivo a essa forma de geração de energia elétrica, que vem crescendo gradativamente.

Esclarece-se, no entanto, já era prevista uma modificação nos subsídios e no incentivo à geração distribuída, porque, na prática, os custos - não absorvidos pelos consumidores de GD - são rateados entre os demais consumidores em uma espécie de subsídio para incentivar a utilização de energias renováveis. Segundo os dados divulgados pela ANEEL, o subsídio teve impacto de R \$ 205 milhões em 2018, e custará entre $\mathrm{R} \$ 11$ bilhões e $\mathrm{R} \$ 13$ bilhões até 2025 .

A ANEEL tem a intenção de passar a cobrar os custos da distribuição de energia também dos consumidores de geração distribuída. A cobrança seria implementada de forma escalonada; a partir de 2020, novos consumidores de geração distribuída local pagariam os custos da rede; até 2030, ou quanto a capacidade de geração distribuída no País alcançar 5,9 GW, esses consumidores passariam a arcar, também, com os encargos respectivos. Para os consumidores já ativos na geração distribuída, as novas regras passariam a valer apenas em 2031.

A agência regulatória argumenta que essa alteração é necessária para garantir o crescimento sustentável do sistema, sem que isso acarrete num aumento de preço das tarifas de energia elétrica, uma vez que o sistema é integralmente interligado - assim como em outras áreas, alguém paga a conta de quem não paga e a modicidade tarifária é um dos princípios basilares do SEB.

Em contrapartida, os críticos da alteração regulatória afirmam que a cobrança, ainda que seja pelo excedente de consumo, acabará por desincentivar mais consumidores a aderirem à geração distribuída, na medida em que o tempo para a compensação do investimento aumentaria (pay back). Porém a polêmica perdura; a ANEEL esticou o prazo para as contribuições da consulta pública sobre o tema até o final de 2019 e, no início de 2020 deparou-se com notícias desencontradas no noticiário a respeito da definição. Várias entidades têm-se colocado contra o formato proposto, especialmente aquelas ligadas às associações de energia limpa e pressionado parlamentares e o Poder Executivo.

Por sua vez, o Presidente da República, que inicialmente disse que não se envolveria no assunto por se tratar de uma questão técnica e que a ANEEL tem atuação 
independente em relação ao Executivo ${ }^{11}$, posteriormente afirmou que houve um consenso para a "não taxação do sol". ${ }^{12}$ A questão ainda carece de decisão, o que deverá o correr nas próximas semanas.

Essa polêmica só demonstra que também em setores altamente regulados como o elétrico, algumas inovações são impossíveis de serem barradas pelo poder público. A velocidade das inovações é avassaladora e se essa celeridade for comparada com a dos entes públicos, ela passa a ser incomparável.

Por mais que o agente regulador tente conter ou prever os avanços nessa área, indubitavelmente, a geração de energia descentralizada crescerá exponencialmente e, para que seja possível essa afirmação, não precisa ser alguém da área de tecnologia ou de energia, basta olhar os avanços ao redor e as experiências de Estados mais desenvolvidos.

Inovações, como carros elétricos que já podem ser carregados nas próprias casas dos consumidores mediante a energia produzida pelos próprios em suas casas, abastecidas por placas fotovoltaicas ou por baterias de hidrogênio, já são realidade.

Por toda a importância do setor já alardeada neste estudo, é estratégico que haja um planejamento para os próximos anos (como de fato há), um acompanhamento eficaz e uma execução perfeita das estratégias, portanto, é imperioso que esse setor seja regulado. Entretanto, fica evidente que o crescimento da geração distribuída no setor elétrico não será acompanhado pelo entes públicos, para os quais restará apenas proteger os consumidores e verificar se a demanda está sendo atendida.

Quanto ao preço, hoje objeto de estudos constantes para a preservação da tarifa justa e módica, provavelmente deixará de ser uma preocupação, pois, com a abertura do mercado, a tendência é de que ocorra uma queda significativa dos valores cobrados; além de prosumidor, o consumidor escolherá com quem e quais serviços agregados ele terá ao seu dispor na Internet da Energia.

No que tange às empresas de distribuição, hoje concessionárias no Brasil, segundo estudos da Boston Consulting Group $^{13}$ as distribuidoras de energia devem rapidamente atentar-se para as ameaças do crescimento da energia solar.

\footnotetext{
11 PODER360. Bolsonaro diz ser contra taxar energia solar, mas que decisão é da Aneel.

Disponível em: <https://www.poder360.com.br/economia/bolsonaro-diz-ser-contra-taxar-energia-solarmas-que-decisao-e-da-aneel/>. Acesso em: 6 jan. 2020.

12 OGLOBO. Bolsonaro diz que não haverá taxação de energia solar. Disponível em: <https://oglobo.globo.com/economia/bolsonaro-diz-que-nao-havera-taxacao-de-energia-solar-24176399>. Acesso em: 7 jan. 2020.
} 
Dentre estas ameaças está a queda de receitas no varejo, pois, sem dúvida as distribuidoras perderão clientes, mas os custos de manutenção e operação da rede elétrica e da geração são fixos. Outro aspecto digno de atenção das concessionárias de distribuição é o aumento da volatilidade da carga induzida pela geração distribuída de energia solar e a tensão operacional que ela pode causar na rede. Segundo um estudo do BCG publicado em 2017:

\begin{abstract}
“(...) quando a produção de energia descentralizada excede o consumo local, a energia reflui para as redes, resultando em sobrecarga e flutuações de tensão, para as quais essas redes podem não estar adequadamente projetadas. Além disso, os níveis acentuados de flutuação da demanda da rede perto das horas de pico levantam problemas de equilíbrio do sistema elétrico que nem sempre são facilmente resolvidos pelas tecnologias tradicionais de controle centralizado.(CORRE, 2017)."
\end{abstract}

Às companhias brasileiras do setor resta uma única saída: proatividade para enfrentar os desafios da energia descentralizada, aceitando que seu crescimento é inevitável e aproveitando as informações e capilaridade de sua base de clientes via smart grids $^{14}$ e outras tecnologias da Internet da Energia como oportunidade de negócios.

\title{
6 CONSIDERAÇÕES FINAIS
}

Segundo Rifkin, no futuro da sociedade de consumo o acesso é mais importante do que a posse, e o capital social vale mais do que o capital financeiro. Assim, num futuro cujas inovações ainda são impossíveis de serem previstas, por certo que os pensadores contemporâneos têm receio do desconhecido e dos rumos que a sociedade irá tomar. O que conforta é o fato de que os nossos antepassados sentiram transições semelhantes entre o sistema feudal e o mercantilista, por exemplo. Vivemos a transição para o que será do mundo na Terceira Revolução, na qual, segundo Rifkin, prevê-se uma horizontalização da cadeia de consumo, a valorização e o empoderamento do indivíduo e da abundância de recursos essenciais.

Todas essas afirmações são uma previsão. É muito difícil precisar-se o futuro econômico e social, tendo em vista que tudo muda muito rápido e em itens basilares de

\footnotetext{
${ }^{13}$ CORRE, Jean Le et alii. Geração de Energia Solar Descentralizada: Cenários e implicações para o setor no Brasil. 3 abr. 2017. Disponível em <https://www.bcg.com/pt-br/perspectives/158398>. Acesso em: 7 jan. 2020.

${ }^{14}$ Em trâmite o Projeto de Lei no Senado Federal sob o n ${ }^{\circ} 356 / 2017$ para a modernização do setor.
} 
várias áreas. Contudo, no que tange a algumas searas, essa previsibilidade é maior. Dentre elas a de energia elétrica destaca-se. Por tudo o que se tem vivenciado deixa com clareza solar a impressão de que num futuro próximo o prosumidor de energia transformará a forma da geração elétrica na medida em que haverá a facilitação do acesso à produção e ao consumo descentralizado, diminuindo a ingerência do Estado sobre a demanda e a regulação.

O Estado, que vem vivenciando essa situação em outras áreas, como no transporte e nos serviços, limitar-se-á por vontade própria ou não a fiscalizar a qualidade dos serviços e acompanhar a execução do setor no aspecto do atendimento da demanda do crescimento sustentável (que ocorrerá mesmo sem a intervenção estatal) e a preços módicos e justos (o que também ocorrerá frente ao aumento da competitividade e do empoderamento dos consumidores, ou prosumidores em muitos casos).

Ao projetar o setor elétrico brasileiro no futuro, sob a perspectiva de uma Sociedade de Custo Marginal Zero, tal qual entende Jeremy Rifkin, vê-se que a tendência é que o País, assim como toda a humanidade, não mais tenha qualquer problema de falta de energia, pois a mesma será abundante, com a utilização de tecnologia para o armazenamento de energias renováveis, tal como a solar, a voltaica, a biomassa e o hidrogênio. Essa utilização naturalmente romperá fronteiras, aumentará a concorrência e a autonomia dos consumidores/prosumidores, barateará muito os custos e facilitará a vida das pessoas, como tem acontecido com a maioria das inovações do século XXI.

É um caminho aparentemente inevitável, que se espera que o Brasil enfrente sem sobressaltos e que melhore a vida dos brasileiros de forma universal, com acesso irrestrito e não apenas para os mais privilegiados.

\section{REFERÊNCIAS}

ABRAMOVAY, Ricardo. A economia híbrida do século XXI. De baixo pra cima. Rio de Janeiro: Aeroplano, 2014.

AFONSO DA, VIRGÍllO. A Constitucionalização do Direito - Os Direitos Fundamentais nas Relações Entre Particulares. São Paulo: Editora Malheiros. 2011.

ANEEL. Disponível em: <http://www.aneel.gov.br/geracao-distribuida>. Acesso em; 5 fev. 2020.

BRAGA, Rodrigo Bernardes. Manual do Direito de Energia Elétrica. Belo Horizonte. Editora D'Plácido, 2018. 
CCEE. Disponível em: <https://www.ccee.org.br/portal/faces/pages_publico/ondeatuamos/setor_eletrico?_afrLoop=1469887863935266\&_adf.ctrl-state=bkz9tq9sh_27.>. Acesso em: 5 fev. 2020.

CORRE, Jean Le et alii. Geração de Energia Solar Descentralizada: Cenários e implicações para o setor no Brasil. 3 abr. 2017. Disponível em <https://www.bcg.com/pt-br/perspectives/158398>. Acesso em: 7 jan. 2020.

DAVID, Solange, e VIANA, Alexandre. O papel do Estado Brasileiro na Regulação e no desenho do Mercado de Energia Elétrica. Temas relevantes do Direito de Energia Elétrica. Fábio Amorim da Rocha Coordenador. Rio de Janeiro: Editora Synergia, 2016.

FIORILLO, Celso Antônio Pacheco; FERREIRA, Renata Marques. PARÂMETROS NORMATIVOS VINCULADOS AO USO DA ENERGIA SOLAR NO PAÍS EM FACE DO DIREITO AMBIENTAL BRASILEIRO. Revista Juridica, [S.1.], v. 51, n. 2, p. 182 - 210, abr. 2018. ISSN 2316-753X. Disponível em: <http://revista.unicuritiba.edu.br/index.php/RevJur/article/view/2805/371371473>.

Acesso em: 18 abr. 2020. doi:http://dx.doi.org/10.21902/revistajur.2316753X.v51i2.2805.

IEA. Shapping a secure and sustainable energy future for all. Disponível em: <https://www.iea.org/>. Acesso em: 3 fev. 2020.

KAFRUNI, Simone. Sem energia fornecida pela Venezuela, Roraima pode ficar no escuro. In: Correio Braziliense. Disponível em: <https://www.correiobraziliense.com.br/app/noticia/brasil/2018/08/23/internabrasil,701615/roraima-pode-ficar-no-escuro-sem-energia-fornecida-pelavenezuela.shtml>. Acesso em: 5 fev. 2020.

MALDONADO, Glesler Sales; LANNES, Yuri Nathan da Costa. Análise da constitucionalidade do impedimento de empresas geradoras de energia elétrica optarem pelo regime diferenciado de tributação - simples nacional. Revista Juridica, [S.1.], v. 1, n. 46, p. 258-280, jul. 2017. ISSN 2316-753X. Disponível em: <http://revista.unicuritiba.edu.br/index.php/RevJur/article/view/2008/1289>. Acesso em: 14 abr. 2020. doi:http://dx.doi.org/10.21902/revistajur.2316-753X.v1i46.2008.

NOS. Disponível em:< http://www.ons.org.br/paginas/sobre-o-sin/o-que-e-o-sin>. Acesso em: 6 fev. 2020.

OGLOBO. Bolsonaro diz que não haverá taxação de energia solar. Disponível em: $<$ https://oglobo.globo.com/economia/bolsonaro-diz-que-nao-havera-taxacao-de-energiasolar-24176399>. Acesso em: 7 jan. 2020.

PODER360. Bolsonaro diz ser contra taxar energia solar, mas que decisão é da Aneel. Disponível em: <https://www.poder360.com.br/economia/bolsonaro-diz-sercontra-taxar-energia-solar-mas-que-decisao-e-da-aneel/>. Acesso em: 6 jan. 2020.

RIFKIN, Jeremy. Sociedade de Custo Marginal Zero. São Paulo: M. Books do Brasil Ltda., 2016. 
RIFKIN, Jeremy. Sociedade de Custo Marginal Zero. São Paulo: M. Books do Brasil Ltda., 2016.

RIFKIN, Jeremy. A economia do Higrogênio: a criação de uma nova fonte de energia e a redistribuição do poder na Terra. São Paulo: M. Brooks Editora, 2003.

COSTA, Guilherme Ferreira da. Universidade Federal do Rio de Janeiro. Instituto de Economia. Monografia de Bacharelado. Economia Compartilhada: Um novo paradigma? 2017.

TOFFLER, Alvin. Terceira Onda. São Paulo: Editora Record, 1980.

. Power Shift: as mudanças do poder. Rio de Janeiro: Record, 1990. 